\title{
Antimicrobial resistance in Neisseria gonorrhoeae isolates and gonorrhoea treatment in the Republic of Belarus, Eastern Europe, 2009-2019
}

\section{Aliaksandra Aniskevich}

Belarusian Medical Academy of Post-Graduate Education

Iryna Shimanskaya

Belarusian Medical Academy of Post-Graduate Education

Iryna Boiko

WHO Collaborating Centre for Gonorrhoea and other STIs, Örebro University

Tatyana Golubovskaya

Mogilev Regional Skin and Venereal Diseases Dispensary

\section{Daniel Golparian}

WHO Collaborating Centre for Gonorrhoea and other STIs, Örebro University

Iryna Stanislalova

Mogilev Skin and Venereal Diseases Dispensary

\section{Susanne Jacobsson}

WHO Collaborating Centre for Gonorrhoea and other STIs, Örebro University

\section{Aliaksandr Adaskevich}

Mogilev Regional Skin and Venereal Diseases Dispensary

Magnus Unemo ( $\square$ magnus_unemo@yahoo.com )

WHO Collaborating Centre for Gonorrhoea and other STIs. Örebro University Hospital https://orcid.org/0000-0003-1710-2081

\section{Research article}

Keywords: Neisseria gonorrhoeae; antimicrobial resistance; surveillance; treatment; ceftriaxone; azithromycin; Belarus; Eastern Europe.

Posted Date: August 26th, 2020

DOI: https://doi.org/10.21203/rs.3.rs-61686/v1

License: (c) (i) This work is licensed under a Creative Commons Attribution 4.0 International License. Read Full License 
Version of Record: A version of this preprint was published at BMC Infectious Diseases on June 2nd, 2021. See the published version at https://doi.org/10.1186/s12879-021-06184-7. 
RESEARCH ARTICLE

Antimicrobial resistance in Neisseria gonorrhoeae isolates and gonorrhoea treatment in the Republic of Belarus, Eastern Europe, 2009-2019

Aliaksandra Aniskevich ${ }^{1}$

Email: dr.aniskevich@gmail.com

Iryna Shimanskaya ${ }^{1}$

Email: shimanskayai@yahoo.com

Iryna Boiko ${ }^{2,3}$

Email: iryna.boiko.ua@gmail.com

Tatyana Golubovskaya ${ }^{4}$

Email:mogilev.derma@mail.ru

Daniel Golparian ${ }^{3}$

Email: daniel.golparian@regionorebrolan.se

Iryna Stanislavova ${ }^{4}$

Email:mogilev.derma@mail.ru

Susanne Jacobsson ${ }^{3}$

Email: susanne.jacobsson@regionorebrolan.se

Aliaksandr Adaskevich ${ }^{4}$

Email:mogilev.derma@mail.ru

Magnus Unemo ${ }^{3, *}$

Email: magnus_unemo@yahoo.com

*Corresponding author 
${ }^{1}$ Belarusian Medical Academy of Postgraduate Education, Minsk, Belarus

${ }^{2}$ Department of Functional and Laboratory Diagnostics, I. Horbachevsky Ternopil National Medical University, Ternopil, Ukraine

${ }^{3}$ World Health Organization Collaborating Centre for Gonorrhoea and Other Sexually Transmitted Infections (STIs), National Reference Laboratory for STIs, Department of Laboratory Medicine, Clinical Microbiology, Faculty of Medicine and Health, Örebro University, Örebro, Sweden

${ }^{4}$ Mogilev Regional Skin and Venereal Diseases Dispensary, Mogilev, Belarus Correspondence: magnus_unemo@yahoo.com. M. Unemo, WHO Collaborating Centre for Gonorrhoea and Other STIs, National Reference Laboratory for STIs, Department of Laboratory Medicine, Clinical Microbiology, Örebro University Hospital, SE-701 85 Örebro, Sweden. Tel: $+46-19-602038$

Running head: Gonococcal antimicrobial resistance in Belarus, 2009-2019 Abstract: 349 words

Manuscript: 2722 words

Tables: 2

Figures: 1

\begin{abstract}
Background: Increasing antimicrobial resistance (AMR) in Neisseria gonorrhoeae, including to first-line treatment options, is a great concern worldwide. However, very limited gonococcal AMR data are available in Eastern Europe. We investigated the AMR in N. gonorrhoeae isolates $(\mathrm{n}=522)$ cultured in three regions of the Republic of Belarus, 2009-2019, antimicrobial treatment recommended nationally, and treatment given to 1652 gonorrhoea patients in two of the regions (Minsk, 2013-2018; Mogilev, 2010-2019).
\end{abstract}


Methods: Determination of minimum inhibitory concentrations (MICs) of eight antimicrobials was performed using Etest and, where available, resistance breakpoints from the European Committee on Antimicrobial Susceptibility Testing were applied. $\beta$-lactamase production was examined using a Nitrocefin test. Gonorrhoea treatment was analysed from medical records.

Results: In total, $27.8 \%$ of isolates were resistant to tetracycline, $24.7 \%$ to ciprofloxacin, $7.0 \%$ to benzylpenicillin, $2.7 \%$ to cefixime, and $0.8 \%$ to azithromycin. No isolates were resistant to ceftriaxone, spectinomycin, or gentamicin. However, four $(0.8 \%)$ isolates had a ceftriaxone MIC of $0.125 \mathrm{mg} / \mathrm{L}$, which is exactly at the resistance breakpoint $(\mathrm{MIC}>0.125$ $\mathrm{mg} / \mathrm{L})$. Only one $(0.2 \%)$ isolate, from 2013, produced $\beta$-lactamase. From 2009-2019, the levels of resistance to ciprofloxacin and tetracycline were relatively stably high. Resistance to cefixime was not identified before 2013 , but peaked at $22.2 \%$ in 2017 . Only sporadic isolates with resistance to azithromycin were found in $2009(n=1), 2012(n=1)$ and 2018-2019 (n=2). Overall, $862(52.2 \%)$ patients received first-line treatment in accordance with national guidelines (ceftriaxone $1 \mathrm{~g}$ ). However, 154 (9.3\%) patients received a nationally recommended alternative treatment (cefixime $400 \mathrm{mg}$ or ofloxacin $400 \mathrm{mg}$ ), and $636(38.5 \%)$ patients were given treatment non-compliant to the Belarusian national gonorrhoea guideline.

Conclusions: Ceftriaxone $1 \mathrm{~g}$, in combination with azithromycin $2 \mathrm{~g}$ particularly when chlamydial infection has not been excluded, should be recommended as empiric first-line treatment. Spectinomycin $2 \mathrm{~g}$, where available, together with azithromycin $2 \mathrm{~g}$ could be an alternative treatment. When susceptibility has not been confirmed by testing, fluoroquinolones should not be used for treatment. Timely updating of and high compliance to national evidence-based gonorrhoea treatment guidelines that are based on quality-assured AMR data is imperative. Continued and expanded gonococcal AMR surveillance in Belarus is crucial. 
Keywords: Neisseria gonorrhoeae; antimicrobial resistance; surveillance; treatment; ceftriaxone; azithromycin; Belarus; Eastern Europe.

\section{Background}

Gonorrhoea is one of the most common sexually transmitted infections (STIs) worldwide [13]. According to the World Health Organization (WHO), in 2016, 86.9 million new cases of gonorrhoea among adults were estimated [2]. In the Republic of Belarus, the incidence of reported gonorrhoea (cases per 100,000 inhabitants) has substantially decreased, i.e., from 63 in 2005 to 44.4 in 2009, and finally to 10.5 in 2018 [4]. However, the reported incidence in Belarus, as well as in many other East-European countries, is most likely underestimated due to limited testing, particularly of extragenital specimens, insufficient use of nucleic acid amplification tests (NAATs), incomplete reporting and epidemiological surveillance [5-7].

Alarmingly, the level of antimicrobial resistance (AMR) in Neisseria gonorrhoeae to a wide range of drugs has increased worldwide, including to first-line treatment $[3,5,8-11]$. The extended-spectrum cephalosporin (ESC) ceftriaxone is the only remaining option for empiric first-line monotherapy in most countries. However, decreased susceptibility or resistance, in vitro and clinical, to ceftriaxone has emerged in many settings globally [3,5,8-28]. Consequently, WHO global gonorrhoea treatment guidelines and guidelines in Europe, Australia, Canada, and USA recommend dual antimicrobial first-line therapies, mainly ceftriaxone 500-1000 mg $\times 1$ intramuscularly (IM) plus azithromycin 1-2 $\mathrm{g} \times 1$ orally $[8,11,29$ 31]. However, some countries such as Japan, Ukraine and, since 2019, the United Kingdom recommend high-dose (mainly $1 \mathrm{~g}$ ) ceftriaxone monotherapy, i.e. when chlamydial infection has been excluded [32-34]. Nevertheless, the first global failure to cure gonorrhoea with dual therapy was reported in 2016 [27] and in 2018 the first gonococcal strain with ceftriaxone 
resistance combined with high-level azithromycin resistance was identified in both England [24] and Australia [35].

WHO has developed a global action plan to control the spread and minimise the impact of AMR in N. gonorrhoeae [10]. One of its key strategies is to enhance the quality-assured gonococcal AMR surveillance globally; to identify emerging AMR, monitor AMR trends, and to ensure effective patient management by timely and evidence-based refinements of treatment guidelines. In the European Union/European Economic Area (EU/EEA), the European Gonococcal Antimicrobial Surveillance Programme (Euro-GASP) is monitoring the AMR since 2004 [12,36-38]. However, in the non-EU/EEA countries of the WHO European Region, gonococcal AMR surveillance is extremely limited [5,6], and only sporadically available in Belarus, Russia and Ukraine [33,39-44].

The empirical treatment of gonococcal infections in Belarus is guided by the Clinical protocol for the diagnosis and treatment of patients with sexually transmitted infections approved by order of the Ministry of Health of the Republic of Belarus 10/29/2009, No. 1020 (below referred to as '2009 Belarusian national gonorrhoea guideline') [45]. For treatment of uncomplicated gonorrhoea, first-line treatment is ceftriaxone $1 \mathrm{~g} \times 1 \mathrm{IM}$; and alternative treatment is cefixime $400 \mathrm{mg} \times 1$ orally or spectinomycin $2 \mathrm{~g} \times 1 \mathrm{IM}$ for men and $4 \mathrm{~g} \times 1 \mathrm{IM}$ for women or ofloxacin $400 \mathrm{mg} \times 1$ orally, or lomefloxacin $800 \mathrm{mg} \times 1$ orally [45]. For treatment of complicated gonorrhoea, ceftriaxone $1 \mathrm{~g}$ IM or IV every 24 hours for 7 days is the recommended first-line therapy; and spectinomycin 2 g IM every 12 hours for 7 days or ofloxacin $200 \mathrm{mg}$ orally every 12 hours for 7-14 days or lomefloxacin $400 \mathrm{mg}$ orally every 24 hours for 7-14 days are recommended alternative regimens [45]. Notable, spectinomycin is currently not available in all settings of Belarus [46].

The objectives of the present study were to analyse the trends in N. gonorrhoeae AMR levels in Belarus (2009-2019), review the antimicrobial treatments recommended nationally 
as well as compliance to these recommendations in Belarus, and provide quality-assured gonococcal AMR data for informing the 2009 Belarusian national gonorrhoea guideline [45].

\section{Methods}

\section{Study population}

Gonorrhoea patients $(n=522)$ diagnosed at the following STI Healthcare Institutions: Mogilev Regional Dermatovenerologic Dispensary, Mogilev $(n=409)$, Minsk City Clinical Dermatovenerologic Dispensary, Minsk $(n=83)$ and Vitebsk Regional Dermatovenerologic Dispensary, Vitebsk $(\mathrm{n}=30)$ in Belarus, September 2009-June 2015 and July 2017-December 2019 were included in the study. For description of longitudinal AMR data, this cohort includes previously published data (273 patients) from 2009 ( $n=80)$ [39] and 2010-2013 $(n=193)$ [40]. Cervical specimens from females and urethral specimens from males were collected and delivered to the bacteriological laboratory in Amies Transport Medium with Charcoal (Research and production center Chemmedsynthsis, Minsk, Belarus). Demographic data (gender and age) were collected. Informed consent was obtained from all patients. Exclusion criteria were: i) not confirmed gonococcal infection or ii) not providing informed consent. All patients and their sexual partners were aimed to be managed in accordance with the 2009 Belarusian national gonorrhoea guideline [45].

\section{Culture of Neisseria gonorrhoeae}

All urogenital swabs were inoculated on the selective Chocolate agar ${ }^{\mathrm{TM}}+$ PolyViteX VCAT3 media (bioMerieux, Marcy-l'Etoile, France), followed by incubation in $5 \pm 1 \% \mathrm{CO}_{2}$-enriched humid atmosphere at $36 \pm 1^{\circ} \mathrm{C}$ for $24 \mathrm{~h}$, and - if negative - for additional $24 \mathrm{~h}$. Isolates were confirmed as $N$. gonorrhoeae based on identification of Gram-negative diplococci in microscopy, rapid oxidase reaction, a Vitek ${ }^{\circledR} 2$ automatic bacteriological analyser 
(bioMerieux, Durham, NC, USA) with Vitek ${ }^{\circledR} 2$ NH ID cards (bioMerieux, Marcy-l'Etoile, France), a polymerase chain reaction assay (AmpliSens Neisseria gonorrhoeae-screen-Fl; InterLabServices, Moscow, Russia), and matrix-assisted laser desorption-ionisation time-offlight mass spectrometry (MALDI-TOF MS; Microflex LT, Bruker Daltonik, Bremen, Germany), according to manufacturer's instructions.

The isolates were stored in a liquid preservation medium containing trypticase-soy broth, yeast extract, agar and horse serum, in liquid nitrogen $\left(-196^{\circ} \mathrm{C}\right)$ or in a low-temperature freezer $\left(-80^{\circ} \mathrm{C}\right)$.

\section{Antimicrobial susceptibility testing}

At the WHO Collaborating Centre for Gonorrhoea and other STIs, Sweden, the minimum inhibitory concentrations (MICs; mg/L) of eight antimicrobials (ceftriaxone, cefixime, azithromycin, spectinomycin, ciprofloxacin, tetracycline, benzylpenicillin, and gentamicin) were determined by Etest (bioMerieux, Marcy-l'Etoile, France), following manufacturer's instructions and as described previously $[39,40]$. Results were interpreted using whole MIC dilutions and, where available, clinical breakpoints for susceptibility (S) and resistance (R) according to the European Committee on Antimicrobial Susceptibility Testing (EUCAST) [47]. For azithromycin, no clinical breakpoints exist, and the EUCAST azithromycin epidemiological cut-off value (ECOFF) of MIC $>1 \mathrm{mg} / \mathrm{L}$ [47] was used to indicate isolates with azithromycin resistance determinants (considered as azithromycin resistant below). For gentamicin, previously published interpretative criteria were used [48]. $\beta$-lactamase production was identified using a Nitrocefin test (Oxoid, Basingstoke, England). The 2016 WHO N. gonorrhoeae reference strains [49] were used for quality controls. 


\section{Treatment of gonorrhoea}

The medical records of gonorrhoea patients $(n=1652)$ diagnosed and treated at the Minsk City Clinical Dermatovenerologic Dispensary in 2013-2018 ( $\mathrm{n}=749)$ and Mogilev Regional Dermatovenerologic Dispensary in 2010-2019 (n=903) were analysed. Uncomplicated and complicated gonorrhoea cases were defined according to the international statistical classification of diseases and related health problems [50]. Gonorrhoea treatment compliance to the 2009 Belarusian national gonorrhoea guideline [45] was evaluated.

\section{Statistical analysis}

Statistical analysis was performed using the MedCalc Statistical Software v18.11.3 (MedCalc Software bvba, Ostend, Belgium). The 95\% confidence interval (95\% CI) was calculated using the exact binominal distribution method. Z-test, Fisher exact and Mann-Whitney U tests were used for comparison between groups, as appropriate. The level of significance was set at $\mathrm{P}<0.05$.

\section{Results}

\section{Patients and Neisseria gonorrhoeae isolates characteristics}

N. gonorrhoeae isolates (one per patients) from urogenital sites of 522 patients were examined; $430(82.4 \%)$ males, 84 (16.1\%) females and eight (1.5\%) with gender not reported. The isolates were cultured in Mogilev (78.4\%, 409/522), the capital city Minsk (15.9\%, 83/522), and Vitebsk (5.7\%, 30/522), in $2009(n=81), 2010(n=72), 2011(n=6), 2012(n=75)$, $2013(\mathrm{n}=101), 2014(\mathrm{n}=56), 2015(\mathrm{n}=17), 2017(\mathrm{n}=36)$, in $2018(\mathrm{n}=19)$, and $2019(\mathrm{n}=59)$.

Demographic data (gender and age) were available from 514 (98.5\%) patients. Briefly, the median age for the males was 25 years (range: 16-61 years) and for the females 25 years (range: 16-74 years). The gender and age distributions were relatively similar during 2009- 
2019. The median of male/female ratio was 5.9 (range: 1.8-7.6), with decreasing trends over the years.

Antimicrobial susceptibility of Neisseria gonorrhoeae isolates $(\mathrm{n}=522)$ from Belarus, 2009-2019

The overall antimicrobial susceptibility of all $N$. gonorrhoeae isolates $(\mathrm{n}=522)$ is summarised in Table 1. 
Table 1 Antimicrobial susceptibility in Neisseria gonorrhoeae isolates (n=522) from Minsk, Mogilev and Vitebsk, Belarus, $2009-2019$

\begin{tabular}{|c|c|c|c|c|c|c|c|c|}
\hline \multirow[b]{2}{*}{ Antimicrobials } & \multicolumn{7}{|c|}{ Susceptible (S)/Susceptible, increased exposure (I)/Resistant (R), \% ${ }^{\mathrm{a}}$} & \multirow[b]{2}{*}{ Total $^{\mathrm{b}}$} \\
\hline & $2009^{b}$ & $2010-2011^{b}$ & $2012^{\mathrm{b}}$ & $2013^{\mathrm{b}}$ & 2014-2015 & 2017 & 2018-2019 & \\
\hline & $\mathrm{n}=81$ & $\mathrm{n}=78$ & $\mathrm{n}=75$ & $\mathrm{n}=101$ & $\mathrm{n}=73$ & $\mathrm{n}=36$ & $\mathrm{n}=78$ & $\mathrm{n}=522$ \\
\hline $\mathrm{CRO}$ & $100 / \mathrm{NA} / 0$ & $100 / \mathrm{NA} / 0$ & $100 / \mathrm{NA} / 0$ & $100 / \mathrm{NA} / 0$ & $100 / \mathrm{NA} / 0$ & $100 / \mathrm{NA} / 0$ & $100 / \mathrm{NA} / 0$ & $100 / \mathrm{NA} / 0$ \\
\hline CFM & $100 / \mathrm{NA} / 0$ & $100 / \mathrm{NA} / 0$ & $100 / \mathrm{NA} / 0$ & $98.0 / \mathrm{NA} / 2.0$ & $100 / \mathrm{NA} / 0$ & $77.8 / \mathrm{NA} / 22.2$ & 94.9/NA/5.1 & $97.3 / \mathrm{NA} / 2.7$ \\
\hline AZM & 98.8/NA/1.2 & $100 / \mathrm{NA} / 0$ & 98.7/NA/1.3 & $100 / \mathrm{NA} / 0$ & $100 / \mathrm{NA} / 0$ & $100 / \mathrm{NA} / 0$ & 97.4/NA/2.6 & $99.2 / \mathrm{NA} / 0.8$ \\
\hline SPC & $100 / \mathrm{NA} / 0$ & $100 / \mathrm{NA} / 0$ & $100 / \mathrm{NA} / 0$ & $100 / \mathrm{NA} / 0$ & $100 / \mathrm{NA} / 0$ & $100 / \mathrm{NA} / 0$ & $100 / \mathrm{NA} / 0$ & $100 / \mathrm{NA} / 0$ \\
\hline CIP & $65.4 / 0 / 34.6$ & $64.1 / 2.6 / 33.3$ & $78.7 / 0 / 21.3$ & $72.3 / 0 / 27.7$ & $90.4 / 0 / 9.6$ & $69.4 / 0 / 30.6$ & $83.3 / 0 / 16.7$ & $74.9 / 0.4 / 24.7$ \\
\hline PEN & $29.6 / 60.5 / 9.9$ & $-/-/-$ & $62.6 / 30.7 / 6.7$ & $59.4 / 31.7 / 8.9$ & $80.8 / 16.4 / 2.8$ & $55.6 / 33.3 / 11.1$ & $51.3 / 44.9 / 3.8$ & $56.3 / 36.7 / 7.0$ \\
\hline TET & $55.5 / 21 / 23.5$ & $56.4 / 10.3 / 33.3$ & $56 / 9.3 / 34.7$ & $62.4 / 8.9 / 28.7$ & $76.7 / 5.5 / 17.8$ & $69.4 / 0 / 30.6$ & $61.5 / 11.5 / 26.9$ & $61.9 / 10.3 / 27.8$ \\
\hline GEN & $72.8 / 27.2 / 0$ & $97.4 / 2.6 / 0$ & $58.7 / 41.3 / 0$ & $40.6 / 59.4 / 0$ & $67.1 / 32.9 / 0$ & $55.6 / 44.4 / 0$ & $87.2 / 12.8 / 0$ & $68.4 / 31.6 / 0$ \\
\hline
\end{tabular}

CRO, ceftriaxone; CFM, cefixime; AZM, azithromycin; SPC, spectinomycin; CIP, ciprofloxacin; PEN, benzylpenicillin; TET, tetracycline; GEN, gentamicin;

NA, not applicable; -, not tested.

${ }^{\mathrm{a}}$ The clinical breakpoints (susceptible, resistant) were as follows: ceftriaxone and cefixime (MIC $\leq 0.125 \mathrm{mg} / \mathrm{L}, \mathrm{MIC}>0.125 \mathrm{mg} / \mathrm{L}$ ), ciprofloxacin (MIC $\leq 0.032$ $\mathrm{mg} / \mathrm{L}, \mathrm{MIC}>0.064 \mathrm{mg} / \mathrm{L})$, azithromycin $(\mathrm{MIC} \leq 1 \mathrm{mg} / \mathrm{L}, \mathrm{MIC}>1 \mathrm{mg} / \mathrm{L})$, spectinomycin $(\mathrm{MIC} \leq 64 \mathrm{mg} / \mathrm{L}, \mathrm{MIC}>64 \mathrm{mg} / \mathrm{L})$, benzylpenicillin $(\mathrm{MIC} \leq 0.064 \mathrm{mg} / \mathrm{L}$, $\mathrm{MIC}>1.0 \mathrm{mg} / \mathrm{L})$, tetracycline $(\mathrm{MIC} \leq 0.5 \mathrm{mg} / \mathrm{L}, \mathrm{MIC}>1.0 \mathrm{mg} / \mathrm{L})$, and gentamicin $(\mathrm{MIC} \leq 4 \mathrm{mg} / \mathrm{L}, \mathrm{MIC}>16 \mathrm{mg} / \mathrm{L})[47,48]$.

${ }^{\mathrm{b}}$ Of the 335 isolates from 2009-2013, 273 have been previously published [39,40] 
Briefly, in 2018-2019 the resistance to tetracycline, ciprofloxacin, cefixime, benzylpenicillin, and azithromycin was $26.9 \%, 16.7 \%, 5.1 \%, 3.8 \%$, and 2.6\%, respectively. During 2009-2019, the resistance levels were as follows: tetracycline $27.8 \%$ (range: $17.8-34.7 \%$ ), ciprofloxacin $24.7 \%$ (9.6-34.6\%), benzylpenicillin $7.0 \%(2.8-11.1 \%)$, cefixime $2.7 \%(0-22.2 \%)$, and azithromycin $0.8 \%(0-2.6 \%)$ (Table 1$)$. Only one $(0.2 \%) \beta$-lactamase producing isolate was found (in 2013). No isolates resistant to ceftriaxone, spectinomycin or gentamicin were detected (Table 1). However, four (0.8\%) isolates had a ceftriaxone MIC of $0.125 \mathrm{mg} / \mathrm{L}$, which is exactly at the resistance breakpoint (MIC $>0.125 \mathrm{mg} / \mathrm{L}$ ), and $31.6 \%$ of isolates had a decreased susceptibility to gentamicin.

During 2009-2019, the levels of resistance to tetracycline were relatively stably high. The level of resistance to ciprofloxacin significantly decreased to $9.6 \%$ in $2014-2015$, but subsequently significantly increased to $30.6 \%$ in $2017(\mathrm{P}<0.05)$. The levels of resistance to benzylpenicillin non-significantly fluctuated, i.e. from $2.8 \%$ to $11.1 \%$ over the years. Notable, no resistance to cefixime was found prior to 2013 (when 2.0\% resistance was detected), however, the cefixime resistance then significantly increased to a peak of $22.2 \%$ in 2017 $(\mathrm{P}<0.05)$. Only sporadic isolates with resistance to azithromycin were found in 2009 ( $\mathrm{n}=1$, $1.2 \%), 2012(\mathrm{n}=1,1.3 \%)$ and $2018-2019(\mathrm{n}=2,2.6 \%) \quad($ Table 1$)$.

The MIC distributions for ceftriaxone and azithromycin, included in the internationally recommended first-line dual antimicrobial therapy [8,11,29-31], and cefixime are presented in figure 1 . 


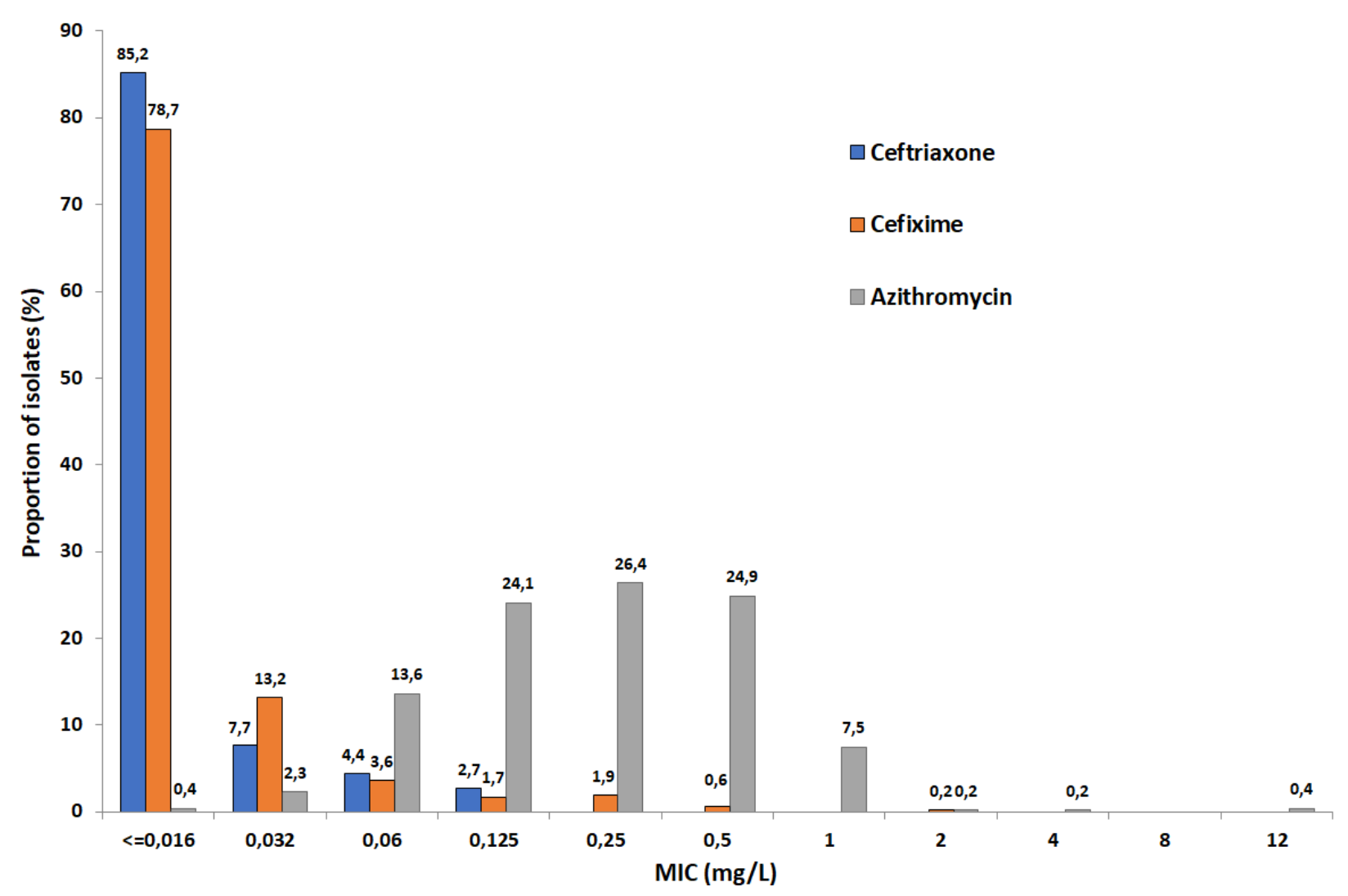

Figure 1. MIC distributions for ceftriaxone, cefixime and azithromycin for Neisseria gonorrhoeae isolates $(\mathrm{n}=522)$ from Belarus, 2009-2019

In total, $0.8 \%(4 / 522)$ of isolates had a ceftriaxone MIC of $0.125 \mathrm{mg} / \mathrm{L}$, which is at the ceftriaxone resistance breakpoint [47]: $1.2 \%(1 / 81)$ in 2009, $1 \%(1 / 101)$ in 2013 and 5.6\% $(2 / 36)$ in 2017 . The proportion of isolates with ceftriaxone $\mathrm{MIC} \leq 0.016 \mathrm{mg} / \mathrm{L}$ was $85.2 \%$, and in general, the annual MIC distribution for ceftriaxone appeared to shift to lower MICs during 2009-2019 (data not shown). For cefixime, 78.7\% (411/522) of isolates had a MIC $\leq 0.016$ $\mathrm{mg} / \mathrm{L}$; however, $2.7 \%(14 / 522)$ of isolates were resistant to cefixime, highest $\mathrm{MIC}=2 \mathrm{mg} / \mathrm{L}$ (one isolate in 2013), and additionally 1.7\% (9/522) of isolates had a cefixime MIC of 0.125 $\mathrm{mg} / \mathrm{L}$, i.e. at the cefixime resistance breakpoint [47]. With the exception of four $(0.8 \%)$ azithromycin-resistant isolates (MICs 2-12 $\mathrm{mg} / \mathrm{L}$ ), the azithromycin MIC distribution appeared to represent a wild-type distribution. 


\section{Antimicrobial treatment of gonorrhoea patients in Belarus, 2010-2019}

Compliance to the treatment of gonococcal infections to the 2009 Belarusian national gonorrhoea guideline [45] at the Minsk City Clinical Dermatovenerologic Dispensary (20132018) and Mogilev Regional Clinical Dermatovenerologic Dispensary (2010-2019) for 1652 patients is described in table 2 .

Table 2 Compliance to the 2009 Belarusian national gonorrhoea guideline [45] in Minsk (749 patients, 2013-2018) and Mogilev (903 patients, 2010-2019), Belarus

\begin{tabular}{lcc}
\hline Prescribed antimicrobials & $\begin{array}{c}\text { Minsk, } \\
\text { No. }(\mathbf{\%}, \mathbf{9 5 \%} \mathbf{C I})\end{array}$ & $\begin{array}{c}\text { Mogilev, } \\
\text { No. }(\mathbf{\%}, \mathbf{9 5 \%} \mathbf{C I})\end{array}$ \\
\hline Recommended first-line treatment $[\mathbf{4 5}]$ & & \\
\hline CRO $1 \mathrm{~g} \times 1$ IM (uncomplicated gonorrhoea) or & $354(47.3,43.7-$ & $508(56.3,53.0-59.6)$ \\
CRO $1 \mathrm{~g} \times 1$ IM or IV every 24 hours, 7 days & $51.0)$ & \\
(complicated gonorrhoea) $^{\mathrm{a}}$ & & \\
\hline
\end{tabular}

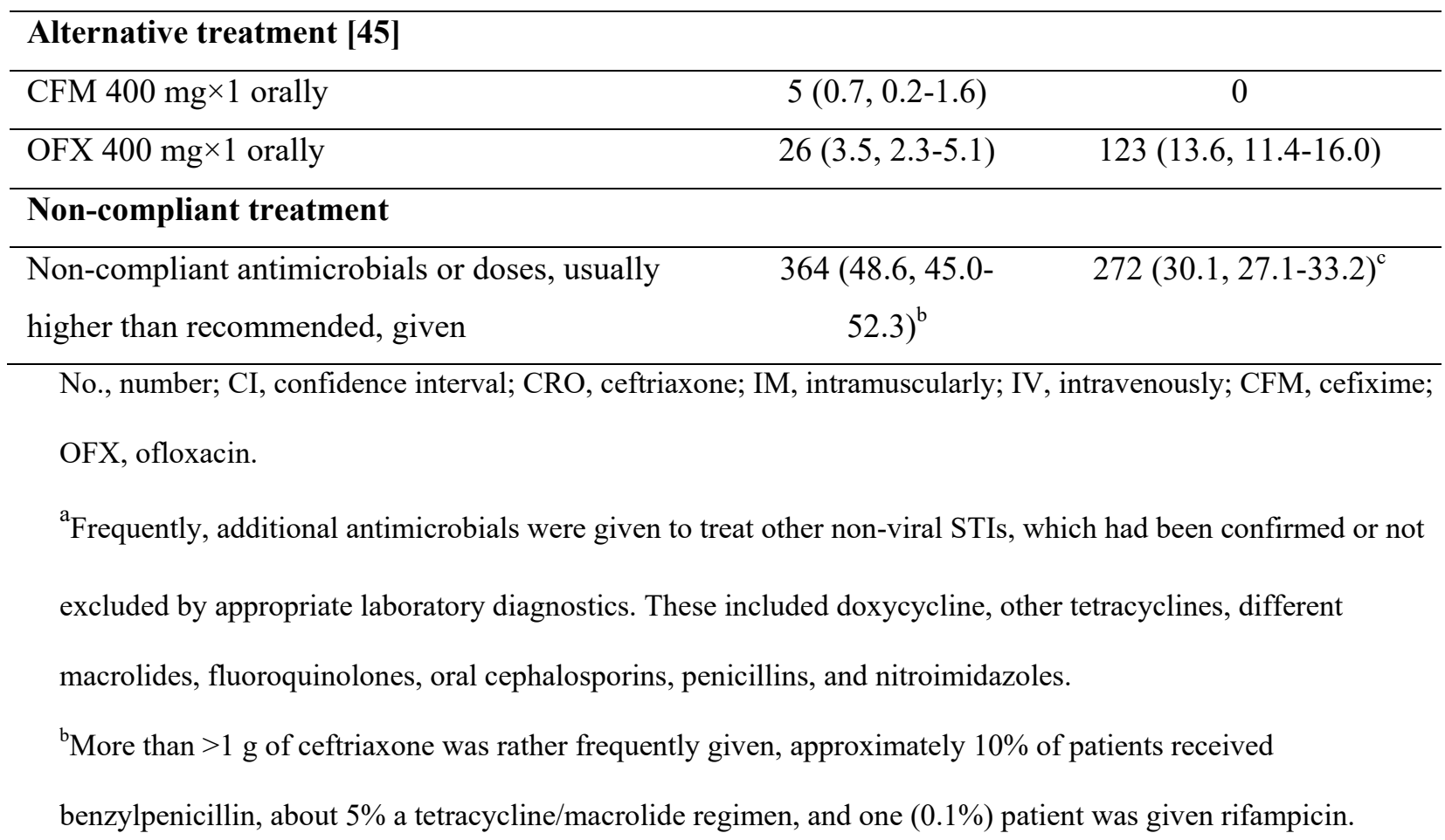


${ }^{\mathrm{c}}$ More than $>1 \mathrm{~g}$ of ceftriaxone was rather frequently given, very rarely a benzylpenicillin regimen was given, and for some few percentages of patients $>400 \mathrm{mg}$ ofloxacin or a tetracycline/macrolide regimen was given.

Many different antimicrobial treatment regimens were administered (Table 2). Overall, only $862(52.2 \%)$ patients received the recommended first-line treatment (ceftriaxone $1 \mathrm{~g}$ (uncomplicated gonorrhoea) or $>1 \mathrm{~g}$ (complicated gonorrhoea) as monotherapy or in combination with other antimicrobials) in accordance with the 2009 Belarusian national gonorrhoea guideline [45], and $154(9.3 \%)$ patients were given a recommended alternative treatment (cefixime $400 \mathrm{mg}$ or ofloxacin $400 \mathrm{mg}$ as a single oral dose) [45]. Consequently, $38.5 \%$ of the patients received treatment not compliant with the 2009 Belarusian national gonorrhoea guideline [45]. Worryingly, despite the high level of ciprofloxacin resistance, ofloxacin $400 \mathrm{mg} \times 1$ was given to $149(9.0 \%)$ patients.

\section{Discussion}

This study describes the first internationally reported gonococcal AMR surveillance data, quality-assured according to WHO standards [5,49,51,52], for isolates cultured in Belarus during an extended time period, i.e., from 2009 to 2019 in Minsk, Vitebsk and Mogilev. The AMR levels were significant and relatively comparable to the neighbouring EU/EEA countries [12,36,37], Russia [41-44], and many other countries globally [5,52]. The AMR levels were also clearly higher than in neighbouring Ukraine [33]. It would be valuable to compare the Belarusian gonococcal population with the $N$. gonorrhoeae strains spreading internationally, i.e. using whole-genome sequencing which is utilised in the Euro-GASP surveillance $[37,53]$ and has also been recently used in the gonococcal AMR surveillance in Ukraine [54] and many other countries globally [55-60].

The prevalence of resistance to the previously recommended gonorrhoea antimicrobials tetracycline, ciprofloxacin, and benzylpenicillin was $27.8 \%, 24.7 \%$ and $7 \%$ respectively, in 
Belarus. None of these antimicrobials should be recommended for empirical first-line gonorrhoea monotherapy in Belarus, which is in concordance with most settings globally [3,5,8-12,28-34,36,37,39-44]. Worryingly, despite the high resistance to ciprofloxacin, the other fluoroquinolones ofloxacin and lomefloxacin remain to be recommended in the 2009 Belarusian national gonorrhoea guideline [45], and particularly ofloxacin was rather frequently used in monotherapy or in combination with other antimicrobials. When susceptibility has not been confirmed by laboratory testing, fluoroquinolones should not be used for treatment [8], and accordingly ofloxacin and lomefloxacin should be excluded from the empiric treatment recommended in the Belarusian national gonorrhoea guideline [45]. Interestingly, $\beta$-lactamase producing gonococcal strains were exceedingly rare $(0.2 \%, 1 / 522$ isolates) in Belarus, which is also a fact in the neighbouring East-European countries Russia and Ukraine $[33,39-44]$. This indicates that no imported $\beta$-lactamase producing strains have managed to establish any domestic transmission and no such strains have emerged in Belarus. However, overall $7 \%$ of isolates had a chromosomally-mediated resistance to benzylpenicillin and additionally $36.7 \%$ of isolates displayed a decreased susceptibility. Azithromycin resistance $(0.8 \%)$ was rare compared to in most EU/EEA countries [12,36,37], and only sporadic isolates $(n=4)$ resistant to azithromycin were found. The overall resistance to cefixime was $2.7 \%$ and the resistance fluctuated from $0 \%$ to $22.2 \%$ in 2017 . However, only 36 gonococcal isolates were examined in 2017 and the high cefixime resistance appeared to be phenotypically represented by a single clone. No gonococcal resistant to ceftriaxone, spectinomycin and gentamicin was identified. However, spectinomycin is currently not available in all settings of Belarus [46]. The lack of ceftriaxone resistance and in general relatively low ceftriaxone MICs may be explained by the long-term use of ceftriaxone $1 \mathrm{~g}$ (in monotherapy or dual therapy) as the recommended empirical first-line treatment of gonorrhoea [45], and the fact that the less potent ESC cefixime has been rarely used for 
treatment of gonorrhoea in Belarus. Worryingly, the compliance to the 2009 Belarusian national gonorrhoea guideline [45] was relatively low and many non-compliant suboptimal antimicrobials were prescribed to a large proportion of patients. This may select for AMR in N. gonorrhoeae, etiological agents of other STIs, and bystander organisms $[3,62]$. Furthermore, in Belarus antimicrobials such as several penicillins and tetracyclines are readily available "over-the-counter" in the pharmacies without any prescriptions, which is crucial to abandon to mitigate self-medication and a further selection of AMR.

The present study has several limitations. Firstly, gonococcal isolates were collected in only three neighbouring regions of the six regions of Belarus. But taking into account that these three regions represent $60 \%$ of the Belarusian population including the capital city Minsk (https://en.wikipedia.org/wiki/Regions_of_Belarus), this geographical bias should be limited and results possible to extrapolate to the whole country. Secondly, the number of isolates per year was low. Thirdly, no pharyngeal or rectal specimens were collected. Finally, no data regarding epidemiological or clinical characteristics such as sexual behaviour and treatment outcomes were collected. Accordingly, the gonococcal AMR surveillance in Belarus should be further strengthened and expanded in Belarus, by increasing the number of representative isolates collected annually, ideally including additional regions, collection of also pharyngeal and rectal specimens and additional epidemiological and clinical data of patients. For this expansion of the gonococcal AMR surveillance, training of clinicians and laboratory workers (e.g., in sample collection, sample transportation, and gonococcal culture), implementation of quality-assured gonococcal culture in additional Belarusian laboratories, and political and financial commitment are imperative. 


\section{Conclusions}

We describe the first internationally reported gonococcal AMR surveillance data for isolates cultured in Belarus during an extended time period, i.e., from 2009 to 2019 in Minsk, Mogilev and Vitebsk regions, quality-assured according to WHO standards [5,49,51,52]. Based on the gonococcal AMR data presented in this paper, Belarus has also been included in the WHO Global GASP [5]. Briefly, in 2009-2019, the gonococcal population in Belarus showed relatively stably high resistance to tetracycline, ciprofloxacin, and benzylpenicillin. More sporadic resistance to azithromycin and fluctuating resistance to cefixime was found. However, no resistance to ceftriaxone, spectinomycin or gentamicin was identified. Accordingly, ceftriaxone $1 \mathrm{~g}$, in combination with azithromycin $2 \mathrm{~g}$ particularly when chlamydial infection has not been excluded, should be recommended as empiric first-line treatment. Spectinomycin $2 \mathrm{~g}$, where available, together with azithromycin $2 \mathrm{~g}$ could be an alternative treatment. When susceptibility has not been confirmed by testing, fluoroquinolones should not be used for treatment. Continued and expanded quality-assured surveillance of gonococcal AMR and ideally also gonorrhoea treatment failures in Belarus is essential to monitor AMR emergence and trends of the susceptibility to particularly ESCs (ceftriaxone and cefixime), azithromycin and doxycycline, and to provide evidence-based AMR data for timely and regular refinements of the national gonorrhoea guideline in Belarus [45], which is essential to ensure effective management and control of gonorrhoea in Belarus.

\footnotetext{
Abbreviations

AMR: antimicrobial resistance; ECOFF: epidemiological cut-off value; ESC: extendedspectrum cephalosporin; EU/EEA: European Union/European Economic Area; EUCAST: European Committee on Antimicrobial Susceptibility Testing; Euro-GASP: European
} 
Gonococcal Antimicrobial Surveillance Programme; IM: intramuscularly; IV: intravenously; MIC: minimum inhibitory concentration; WHO: World Health Organization; 2009 Belarusian national gonorrhoea guideline: Clinical protocol for the diagnosis and treatment of patients with sexually transmitted infections approved by order of the Ministry of Health of the Republic of Belarus 10/29/2009, No. 1020.

\section{Declarations}

\section{Ethics approval and consent to participate}

The present study and publication of its results were approved by the Expert Commission at the Belarusian Medical Academy of Postgraduate Education (BelMAPO), Minsk, Belarus.

\section{Consent for publication}

Not applicable.

\section{Availability of data and materials}

The datasets used and/or analysed during the current study are available from the corresponding author on reasonable request.

\section{Competing interests}

The authors declare that they have no competing interests.

\section{Funding}

The study was supported by the Örebro County Council Research Committee and the Foundation for Medical Research at Örebro University Hospital, Örebro, Sweden.

\section{Authors' contributions}

AAn, ISh and MU designed the study. AAn with support of ISh, IB and MU analysed all the data and wrote the first draft of the manuscript. TG, DG, ISt, SJ, and AAd were involved in collection of samples and/or laboratory examinations. All authors were involved in finalising the manuscript and approved the final version of the manuscript. 


\section{Acknowledgements}

We are very grateful to all the staff at the Mogilev Regional Skin and Venereal Diseases Dispensary and the "Minsk City Clinical Dermatovenerologic Dispensary.

\section{References}

1. Kirkcaldy RD, Weston E, Segurado AC, Hughes G. Epidemiology of gonorrhoea: a global perspective. Sex Health. 2019;16:401-11. https://doi:10.1071/SH19061

2. Rowley J, Vander Hoorn S, Korenromp E, Low N, Unemo M, Abu- Raddad LJ, et al. Chlamydia, gonorrhoea, trichomoniasis and syphilis: global prevalence and incidence estimates, 2016. Bull World Health Organ. 2019;97:548-62. https://doi:10.2471/BLT.18.228486

3. Unemo M, Seifert HS, Hook III EW, Hawkes S, Ndowa F, Dillon JR. Gonorrhoea. Nat Rev Dis Primers. 2019;5(1):79. https://doi:10.1038/s41572-019-0128-6

4. Ministry of Health of the Republic of Belarus State Institution «Republican Scientific and Practical Center for Medical Technologies, Informatization, Administration and Management of Health». Public health in the republic of Belarus: An official statistics collection, 2018. Minsk: RNMB; 2019. 261 p. (in Russian) http://minzdrav.gov.by/upload/dadvfiles/letter/3дравоохранение.pdf (Accessed: July 19, 2020)

5. Unemo M, Lahra MM, Cole M, Galarza P, Ndowa F, Martin I, et al. World Health Organization Global Gonococcal Antimicrobial Surveillance Program (WHO GASP): review of new data and evidence to inform international collaborative actions and research efforts. Sex Health. 2019;16:412-25. https://doi:10.1071/SH19023

6. Unemo M, Ison CA, Cole M, Spiteri G, van de Laar M, Khotenashvili L. Gonorrhoea and gonococcal antimicrobial resistance surveillance networks in the WHO European 
Region, including the independent countries of the former Soviet Union. Sex Transm Infect. 2013;89 Suppl 4:v42-iv6. https://doi:doi:10.1136/sextrans-2012-050909

7. Boiko I, Golparian D, Krynytska I, Unemo M. High prevalence of Chlamydia trachomatis, Neisseria gonorrhoeae and particularly Trichomonas vaginalis diagnosed using US FDA-approved Aptima molecular tests and evaluation of conventional routine diagnostic tests in Ternopil, Ukraine. APMIS. 2019;127:627-34.

8. Unemo M, Ross JDC, Serwin AB, Gomberg M, Cusini M, Jensen JS. 2020 European guideline for the diagnosis and treatment of gonorrhoea in adults. Int J STD AIDS. In Print.

9. Unemo M, Shafer WM. Antimicrobial resistance in Neisseria gonorrhoeae in the $21 \mathrm{st}$ Century: Past, evolution, and future. Clin Microbiol Rev. 2014;27:587-613. https://doi:10.1128/CMR.00010-14

10. World Health Organization (WHO). Global action plan to control the spread and impact of antimicrobial resistance in Neisseria gonorrhoeae. Geneva: WHO, 2012. https://apps.who.int/iris/handle/10665/44863 (Accessed: July 19, 2020)

11. World Health Organization (WHO). WHO guidelines for the treatment of Neisseria gonorrhoeae. Geneva: WHO; 2016 http://www.who.int/reproductivehealth/publications/rtis/gonorrhoea-treatmentguidelines/en/ (Accessed: July 19, 2020)

12. Day MJ, Spiteri G, Jacobsson S, Woodford N, Amato-Gauci AJ, Cole MJ, et al. Stably high azithromycin resistance and decreasing ceftriaxone susceptibility in Neisseria gonorrhoeae in 25 European countries, 2016. BMC Infect Dis. 2018;18(1):609. https://doi:10.1186/s12879-018-3528-4

13. Ohnishi M, Golparian D, Shimuta K, Saika T, Hoshina S, Iwasaku K, et al. Is Neisseria gonorrhoeae initiating a future era of untreatable gonorrhea? Detailed characterisation of 
the first strain with high-level resistance to ceftriaxone. Antimicrob Agents Chemother. 2011;55:3538-45. https://doi:10.1128/AAC.00325-11

14. Cámara J, Serra J, Ayats J, Bastida T, Carnicer-Pont D, Andreu A, Ardanuy C. Molecular characterisation of two high-level ceftriaxone-resistant Neisseria gonorrhoeae isolates detected in Catalonia, Spain. J Antimicrob Chemother. 2012;67:1858-60. https://doi:10.1093/jac/dks162

15. Unemo M, Golparian D, Nicholas R, Ohnishi M, Gallay A, Sednaoui P. High-level cefixime- and ceftriaxone-resistant $N$. gonorrhoeae in France: novel penA mosaic allele in a successful international clone causes treatment failure. Antimicrob Agents Chemother. 2012;56:1273-80. https://doi:10.1128/AAC.05760-11

16. Gianecini R, Oviedo C, Stafforini G, Galarza P. Neisseria gonorrhoeae resistant to ceftriaxone and cefixime, Argentina. Emerg Infect Dis. 2016;22:1139-41. https://doi:10.3201/eid2206.152091

17. Lahra MM, Ryder N, While DM. A new multidrug-resistant strain of Neisseria gonorrhoeae in Australia. N Engl J Med. 2014;371:1850-1. https://doi:10.1056/NEJMc1408109

18. Deguchi T, Yasuda M, Hatazaki K, Kameyama K, Horie K, Kato T, et al. New clinical strain of Neisseria gonorrhoeae with decreased susceptibility to ceftriaxone, Japan. Emerg Infect Dis. 2016;22:142-4. https://doi:10.3201/eid2201.150868

19. Nakayama S-I, Shimuta K, Furubayashi K-I, Kawahata T, Unemo M, Ohnishi M. New ceftriaxone and multidrug-resistant Neisseria gonorrhoeae strain with a novel mosaic penA gene isolated in Japan. Antimicrob Agents Chemother. 2016;60:4339-41. https://doi:10.1128/AAC.00504-16

20. Lahra MM, Martin I, Demczuk W, Jennison AV, Lee KI, Nakayama SI, et al. Cooperative recognition of internationally disseminated ceftriaxone-resistant Neisseria 
gonorrhoeae strain. Emerg Infect Dis. 2018;24:735-40.

https://doi:10.3201/eid2404.171873

21. Lefebvre B, Martin I, Demczuk W, Deshaies L, Michaud S, Labbé AC, et al.

Ceftriaxone-resistant Neisseria gonorrhoeae, Canada, 2017. Emerging Infect Dis. 2018;24:381-3. https://doi:10.3201/eid2402.171756

22. Terkelsen D, Tolstrup J, Johnsen CH, Lund O, Larsen HK, Worning P, et al. Multidrugresistant Neisseria gonorrhoeae infection with ceftriaxone resistance and intermediate resistance to azithromycin, Denmark, 2017. Euro Surveill. 2017;22(42):17-00659. https://doi:10.2807/1560-7917.ES.2017.22.42.17-00659

23. Poncin T, Fouere S, Braille A, Camelena F, Agsous M, Bebear C, et al. Multidrugresistant Neisseria gonorrhoeae failing treatment with ceftriaxone and doxycycline in France, November 2017. Euro Surveill. 2018;23(21):1800264. https://doi:10.2807/15607917.ES.2018.23.21.1800264

24. Golparian D, Rose L, Lynam A, Mohamed A, Bercot B, Ohnishi M, et al. Multidrugresistant Neisseria gonorrhoeae isolate, belonging to the internationally spreading Japanese FC428 clone, with ceftriaxone resistance and intermediate resistance to azithromycin in Ireland, August 2018. Euro Surveill. 2018;23(47):1800617. https://doi:10.2807/1560-7917.ES.2018.23.47.1800617

25. Eyre DW, Sanderson ND, Lord E, Regisford-Reimmer N, Chau K, Barker L, et al. Gonorrhoea treatment failure caused by a Neisseria gonorrhoeae strain with combined ceftriaxone and high-level azithromycin resistance, England, February 2018. Euro Surveill. 2018;23(27):1800323. https://doi:10.2807/1560-7917.ES.2018.23.27.1800323

26. Unemo M. Current and future antimicrobial treatment of gonorrhoea - the rapidly evolving Neisseria gonorrhoeae continues to challenge. BMC Infect Dis. 2015;15:364. doi:10.1186/s12879-015-1029-2 
27. Fifer H, Natarajan U, Jones L, Alexander S, Hughes G, Golparian D, Unemo M. Failure of dual antimicrobial therapy in treatment of gonorrhea. N Engl J Med. 2016;374:2504-6. https://doi:10.1056/NEJMc1512757

28. Lan PT, Golparian D, Ringlander J, Van Hung L, Van Thuong N, Unemo M. Genomic analysis and antimicrobial resistance in Neisseria gonorrhoeae isolates from Vietnam in 2011 and 2015-2016. J Antimicrobial Chemother. 2020;dkaa040. doi:10.1093/jac/dkaa040.

29. Workowski KA, Bolan GA; Centers for Disease Control and Prevention. Sexually transmitted diseases treatment guidelines, 2015. MMWR Recomm Rep. 2015;64(RR-03):1-137.

30. Romanowski B, Robinson J, Wong T. Gonococcal infections chapter. Canadian guidelines on sexually transmitted infections. Wong T, Latham-Carmanico C, editors. Ottawa, ON: Public Health Agency of Canada; 2013. http://www.phac-aspc.gc.ca/stdmts/sti-its/cgsti-ldcits/assets/pdf/section-5-6-eng.pdf_(Accessed: July 19, 2020)

31. Australasian Sexual Health Alliance (ASHA). Gonorrhoea. Australian STI management guidelines for use in primary care: ASHA; 2016. http://www.sti.guidelines.org.au/sexually-transmissibleinfections/gonorrhoea\#management_(Accessed: July 19, 2020)

32. Fifer H, Saunders J, Soni S, Sadiq ST, FitzGerald M. 2018 UK national guideline for the management of infection with Neisseria gonorrhoeae. Int J STD AIDS. 2020;31:4-15. doi:10.1177/0956462419886775

33. Boiko I, Golparian D, Krynytska I, Bezkorovaina H, Frankenberg A, Onuchyna M, et al. Antimicrobial susceptibility of Neisseria gonorrhoeae isolates and treatment of gonorrhoea patients in Ternopil and Dnipropetrovsk regions of Ukraine, 2013-2018. APMIS. 2019;127:503-9. https://doi:10.1111/apm.12948 
34. Japanese Society for Sexually Transmitted Infections. Gonococcal infection. Sexually transmitted infections, diagnosis and treatment guidelines 2011. Jpn J Sex Transm Dis. 2011;22(Suppl. 1):529. (in Japanese)

35. Jennison AV, Whiley D, Lahra MM, Graham RM, Cole MJ, Hughes G, et al. Genetic relatedness of ceftriaxone-resistant and high-level azithromycin resistant Neisseria gonorrhoeae cases, United Kingdom and Australia, February to April 2018. Euro Surveill. 2019;24(8). doi:10.2807/1560-7917.ES.2019.24.8.1900118.

36. Cole MJ, Spiteri G, Jacobsson S, Woodford N, Tripodo F, Amato-Gauci AJ, et al. Overall low extended-spectrum cephalosporin resistance but high azithromycin resistance in Neisseria gonorrhoeae in 24 European countries, 2015. BMC Infect Dis. 2017;17(1):617. https://doi:10.1186/s12879-017-2707-z

37. Harris SR, Cole MJ, Spiteri G, Sánchez-Busó L, Golparian D, Jacobsson S, et al. Public health surveillance of multidrug-resistant clones of Neisseria gonorrhoeae in Europe: a genomic survey. Lancet Infect Dis. 2018;18:758-68. https://doi:10.1016/S1473$\underline{3099(18) 30225-1}$

38. Martin IM, Hoffmann S, Ison CA; ESSTI Network. European Surveillance of Sexually Transmitted Infections (ESSTI): the first combined antimicrobial susceptibility data for Neisseria gonorrhoeae in Western Europe. J Antimicrob Chemother. 2006;58:587-93. https://doi:10.1093/jac/dk1265

39. Glazkova S, Golparian D, Titov L, Pankratova N, Suhabokava N, Shimanskaya I, et al. Antimicrobial susceptibility/resistance and molecular epidemiological characteristics of Neisseria gonorrhoeae in 2009 in Belarus. APMIS. 2011;119:537-42. https://doi:10.1111/j.1600-0463.2011.02770.x

40. Lebedzeu L, Golparian D, Titov L, Pankratava N, Glazkova S, Shimanskaya I, et al. Antimicrobial susceptibility/resistance and NG-MAST characterisation of Neisseria 
gonorrhoeae in Belarus, Eastern Europe, 2010-2013. BMC Infect Dis. 2015;15(1):29. https://doi:10.1186/s12879-015-0755-9

41. Kubanova A, Frigo N, Kubanov A, Sidorenko S, Priputnevich T, Vachnina T, et al. National surveillance of antimicrobial susceptibility in Neisseria gonorrhoeae in 2005-2006 and recommendations of first-line antimicrobial drugs for gonorrhoea treatment in Russia. Sex Transm Infect. 2008;84:285-9. https://doi:10.1136/sti.2007.029033

42. Kubanova A, Frigo N, Kubanov A, Sidorenko S, Lesnaya I, Polevshikova S, et al. The Russian gonococcal antimicrobial susceptibility programme (RU-GASP)-national resistance prevalence in 2007 and 2008, and trends during 2005-2008. Euro Surveill. 2010;15(14):19533. https://doi.org/10.2807/ese.15.14.19533-en

43. Kubanova A, Kubanov A, Frigo N, Solomka V, Semina V, Vorobyev D, et al. Russian gonococcal antimicrobial susceptibility programme (RU-GASP) - resistance in Neisseria gonorrhoeae during 2009-2012 and NG-MAST genotypes in 2011 and 2012. BMC Infect Dis. 2014;14(1):342 https://doi:10.1186/1471-2334-14-342

44. Kubanov A, Vorobyev D, Chestkov A, Leinsoo A, Shaskolskiy B, Dementieva E, et al. Molecular epidemiology of drug-resistant Neisseria gonorrhoeae in Russia (Current Status, 2015). BMC Infect Dis. 2016;16:389. https://doi:10.1186/s12879-016-1688-7

45. Clinical protocol for the diagnosis and treatment of patients with sexually transmitted infections approved by order of the Ministry of Health of the Republic of Belarus 10/29/2009, No. 1020 (“2009 Belarus national gonorrhoea guideline”). (in Russian) https://medznate.ru/docs/index-21995.html?page=2 (Accessed: July 30, 2020)

46. Aniskevich AV, Shimanskaya IG. Antibacterial therapy of racing infections: problems, questions of choice of etiotropic therapy. Military Medicine. 2020;2:28-33. (in Russian) 
47. European Committee on Antimicrobial Susceptibility Testing. Breakpoint tables for interpretation of MICs and zone diameters Version 10.0. https://www.eucast.org/fileadmin/src/media/PDFs/EUCAST_files/Breakpoint_tables/v_1 0.0_Breakpoint_Tables.pdf(Accessed: July 19, 2020)

48. Brown LB, Krysiak R, Kamanga G, Mapanje C, Kanyamula H, Banda B, et al. Neisseria gonorrhoeae antimicrobial susceptibility in Lilongwe, Malawi, 2007. Sex Transm Dis. 2010;37:169-72. https://doi:10.1097/OLQ.0b013e3181bf575c

49. Unemo M, Golparian D, Sanchez-Buso L, Grad Y, Jacobsson S, Ohnishi M, et al. The novel 2016 WHO Neisseria gonorrhoeae reference strains for global quality assurance of laboratory investigations: phenotypic, genetic and reference genome characterisation. J Antimicrob Chemother. 2016;71:3096-108. https://doi:10.1093/jac/dkw288

50. World Health Organization. ICD-10: international statistical classification of diseases and related health problems: tenth revision, version: 2019. World Health Organization. https://icd.who.int/browse10/2019/en (Accessed: July 19, 2020)

51. UNAIDS/WHO Working Group on Global HIV/AIDS and STI Surveillance. Strategies and laboratory methods for strengthening surveillance of sexually transmitted infections 2012. Geneva: World Health Organization; 2012.

http://apps.who.int/iris/bitstream/10665/75729/1/9789241504478 eng.pdf (Accessed: July 19, 2020)

52. Wi T, Lahra MM, Ndowa F, Bala M, Dillon JR, Ramon-Pardo P, et al. Antimicrobial resistance in Neisseria gonorrhoeae: global surveillance and a call for international collaborative action. PLoS Med. 2017;14(7):e1002344.

https://doi:10.1371/journal.pmed.1002344

53. Jacobsson S, Golparian D, Cole M, Spiteri G, Martin I, Bergheim T, et al. WGS analysis and molecular resistance mechanisms of azithromycin-resistant (MIC $>2 \mathrm{mg} / \mathrm{L}$ ) Neisseria 
gonorrhoeae isolates in Europe from 2009 to 2014. J Antimicrob Chemother. 2016;71:3109-16.

54. Boiko I, Golparian D, Jacobsson S, Krynytska I, Frankenberg A, Shevchenko T, et al. Genomic epidemiology and antimicrobial resistance determinants of Neisseria gonorrhoeae isolates from Ukraine, 2013-2018. APMIS. 2020;128:465-75. doi:10.1111/apm.13060

55. Golparian D, Bazzo ML, Golfetto L, Gaspar PC, Schörner MA, Benzaken AS, et al. Genomic epidemiology of Neisseria gonorrhoeae elucidating the gonococcal antimicrobial resistance and lineages/sublineages across Brazil, 2015-2016. J Antimicrob Chemother. In print.

56. Lan PT, Golparian D, Ringlander J, Van Hung L, Van Thuong N, Unemo M. Genomic analysis and antimicrobial resistance of Neisseria gonorrhoeae isolates from Vietnam in 2011 and 2015-16. J Antimicrob Chemother. 2020;75:1432-8. doi:10.1093/jac/dkaa040

57. Grad YH, Harris SR, Kirkcaldy RD et al. Genomic epidemiology of gonococcal resistance to extended-spectrum cephalosporins, macrolides, and fluoroquinolones in the United States, 2000-2013. J Infect Dis. 2016;214:1579-87.

58. Demczuk W, Martin I, Peterson S, Bharat A, Domselaar GV, Graham M, et al. Genomic epidemiology and molecular resistance mechanisms of azithromycin-resistant Neisseria gonorrhoeae in Canada from 1997 to 2014. J Clin Microbiol. 2016;54(5):1304-13. https://doi:10.1128/JCM.03195-15

59. Gianecini RA, Golparian D, Zittermann S, Litvik A, Gonzalez S, Oviedo C, et al. Genome-based epidemiology and antimicrobial resistance determinants in Neisseria gonorrhoeae isolates with decreased susceptibility and resistance to extended-spectrum cephalosporins in Argentina, 2011-2016. J Antimicrob Chemother. 2019;74:1551-9. 
60. Williamson DA, Chow EPF, Gorrie CL, Seemann T, Ingle DJ, Higgins N, et al. Bridging of Neisseria gonorrhoeae lineages across sexual networks in the HIV pre-exposure prophylaxis era. Nat Commun. 2019;10(1):3988. doi:10.1038/s41467-019-12053-4

61. Peng JP, Yin YP, Chen SC, Yang J, Dai XQ, Zheng HP, et al. A whole-genome sequencing analysis of Neisseria gonorrhoeae isolates in China: An observational study. EClinicalMedicine. 2019;7:47-54. doi:10.1016/j.eclinm.2019.01.010

62. Unemo M, Clarke E, Boiko I, Patel C, Patel R. Adherence to the 2012 European Gonorrhoea Guideline in the WHO European Region According to the 2018-19 International Union against Sexually Transmitted Infections European Collaborative Clinical Group Gonorrhoea Survey. Int J STD AIDS. 2020;31(1):69-76. https://doi:10.1177/0956462419879278 
Figures

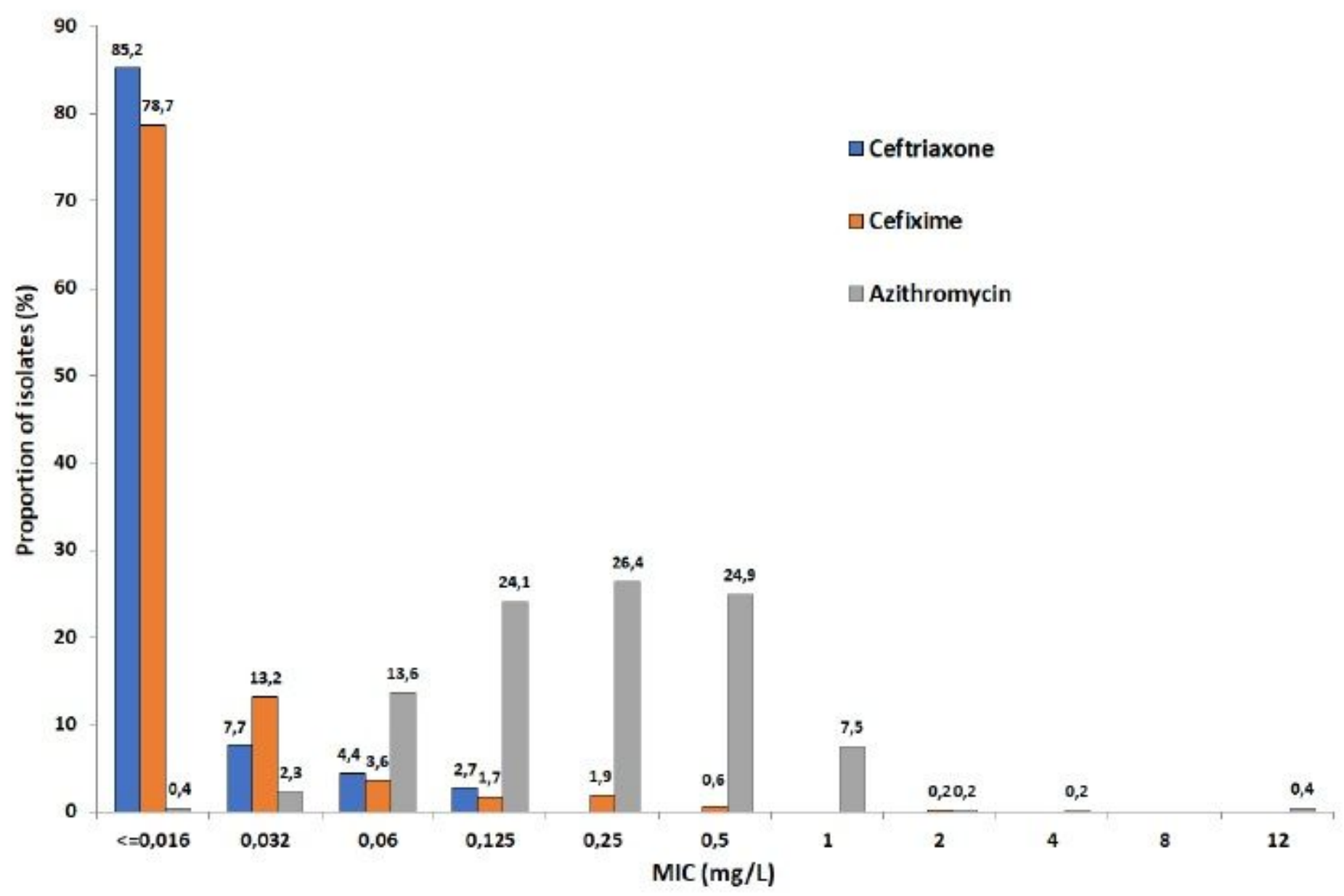

Figure 1

MIC distributions for ceftriaxone, cefixime and azithromycin for Neisseria gonorrhoeae isolates $(n=522)$ from Belarus, 2009-2019 